\title{
Looking for resilience: Understanding the longitudinal trajectories of responses to stress ${ }^{\text {is }}$
}

\author{
Fran H. Norris ${ }^{\mathrm{a}, *}$, Melissa Tracy $^{\mathrm{b}}$, Sandro Galea ${ }^{\mathrm{b}}$ \\ ${ }^{a}$ Dartmouth Medical School, Psychiatry/NCPTSD, VA Medical Center, 215 North Main Street, White River Junction, VT 05009, USA \\ ${ }^{\mathrm{b}}$ University of Michigan, MI, USA
}

\section{A R T I C L E I N F O}

Article history:

Available online 4 May 2009

\section{Keywords:}

Resilience

Disaster

Terrorism

Posttraumatic stress disorder (PTSD)

Mexico

USA

\begin{abstract}
A B S T R A C T
Taking advantage of two large, population-based, and longitudinal datasets collected after the 1999 floods in Mexico $(n=561)$ and the September 11, 2001 terrorist attacks in New York $(n=1267)$, we examined the notion that resilience may be best understood and measured as one member of a set of trajectories that may follow exposure to trauma or severe stress. We hypothesized that resistance, resilience, recovery, relapsing/remitting, delayed dysfunction, and chronic dysfunction trajectories were all possible in the aftermath of major disasters. Semi-parametric group-based modeling yielded the strongest evidence for resistance (no or mild and stable symptoms), resilience (initially moderate or severe symptoms followed by a sharp decrease), recovery (initially moderate or severe symptoms followed by a gradual decrease), and chronic dysfunction (moderate or severe and stable symptoms), as these trajectories were prevalent in both samples. Neither Mexico nor New York showed a relapsing/ remitting trajectory, and only New York showed a delayed dysfunction trajectory. Understanding patterns of psychological distress over time may present opportunities for interventions that aim to increase resilience, and decrease more adverse trajectories, after mass traumatic events.
\end{abstract}

(C) 2009 Elsevier Ltd. All rights reserved.
It has long been observed that people often function remarkably better than objective circumstances suggest they should. For example, many youth experience academic success despite significant childhood adversity (Cowen, Wyman, \& Work, 1996; Garmezy, 1974). In the context of traumatic event experiences, most first responders stay well despite the horrors of their work (Norris et al., 2002; van der Velden et al., 2006) and rates of posttraumatic stress disorder (PTSD) in the general population are far lower than rates of exposure to potentially traumatic events (Breslau et al., 1998). These observations have generated substantial interest in resilience, defined variously as the process of, capacity for, or outcome of successful adaptation after trauma or severe stress (Butler, Morland, \& Leskin, 2007; Egeland, Carlson, \& Sroufe, 1993; Layne, Warren, Watson, \& Shalev, 2007; Masten, Best, \& Garmezy, 1990; Norris, Stevens, Pfefferbaum, Wyche, \& Pfefferbaum, 2008; Werner \& Smith, 1982).

Despite this longstanding interest in resilience, considerable confusion remains with regard to how the concept is best researched. Advancements in understanding resilience have been

\footnotetext{
This research was supported by Grants R01 MH51278, R01 MH66391, and P60 MH082598 from the National Institute of Mental Health.

* Corresponding author. Tel.: +1 8022965132.

E-mail address: fran.norris@dartmouth.edu (F.H. Norris).
}

hampered by two common problems in the research literature. One problem is the frequent assumption that resilience can be inferred on the basis of an absence of psychopathology at a single point in time. Resilience may be manifest in the absence of psychopathology (or more completely in the presence of wellness; see Norris et al., 2008) but the concepts are not synonymous. There are multiple routes to good mental health, of which resilience is just one. Moreover, the absence of psychopathology at one point in time does not assure that it was absent previously or will not occur at some later point in time. The second problem, related to the first, is investigators' loose and post hoc usage of the term resilience to capture all unexamined reasons for failing to find psychopathology following substantial traumatic stress.

However, in recent years there has also been considerable progress on several fronts. These contributions come from various disciplines but share in common a central concern with the timing, duration, and course of responses to stress. First, there is growing consensus that resilience is better characterized as adaptability than as stability (Adger, 2000; Klein, Nicholls, \& Thomalla, 2003). In other words, resilience is a process of "bouncing back" from harm rather than immunity from harm (Garmezy, 1993; Layne et al., 2007). This image can be traced to its origins in mathematics and physics, where resistance was defined as the force (stress) required to displace a system from equilibrium, whereas resilience was 
defined as the time required for the system to return to equilibrium once displaced (Bodin \& Wiman, 2004). In physics, resilience has little to do with how large the initial displacement is or even how severe the oscillations are but is more precisely the speed with which homeostasis is achieved. Applying this analogy to the human stress response, we should use the concept of resistance (not resilience) to describe situations where dysfunction is minimal because coping resources have effectively blocked the stressor. Resistance is an unlikely course in the aftermath of extreme stressors, such as disasters, where distress is nearly universal in the first weeks or months (Norris et al., 2002). Thus, resilience is a different trajectory than is resistance.

Second, it has become increasingly recognized that resilience should be differentiated from recovery. In his influential paper on psychological resilience, Bonanno (2004) characterized recovery as involving a period of dysfunction lasting several months or more, followed by a gradual return to pre-event functioning. Resilience, he argued, may involve transient perturbations, lasting as long as several weeks, but generally involves a stable trajectory of healthy functioning. It is now commonly accepted in the disaster field that some distress is a normal reaction to an abnormal event (Flynn, 1994). Most of the time, however, transient dysfunction is followed by a reasonably rapid return to pre-disaster levels of functioning (Norris et al., 2002). Thus, resilience is a different trajectory than is recovery.

Putting these perspectives together, we suggest, as have some others (Layne et al., 2007), that resilience may be best understood and measured as a trajectory and, more to the point, as one member of a set of possible trajectories that may follow exposure to trauma or severe stress (see Fig. 1). Whereas trauma refers to a sudden experience or confrontation with actual or threatened death or serious injury (American Psychiatric Association, 1994), severe stress is a broader construct referring to various losses, uncertainties, challenges and demands. In addition to resistance, resilience, and recovery trajectories, there are at least three other trajectories of potential interest in research about the consequences of stressful events: relapsing/remitting, in which symptoms display a cyclical course; delayed dysfunction, in which PTSD or some other trauma-related disorder emerges after considerable time has passed; and chronic dysfunction, where an initial stress reaction persists.

Longitudinal research on trauma and bereavement substantiates the presence of distinct symptom trajectories over time. Orcutt, Erickson, and Wolfe (2004) studied a predominantly male sample of Gulf War veterans within five days of their return to the United States and approximately 2 and 6 years later. Two distinct growth curves characterized the data. The largest group of veterans showed low levels of PTSD symptoms initially and little change. The other group showed slightly higher symptoms initially, followed by significant increases over time. These trends would be most consistent with our proposed resistance and delayed dysfunction trajectories, but the long intervals may have made it difficult to capture other potential patterns and the nature of the sample precludes broad generalization. O'Donnell, Elliott, Lau, and Creamer (2007) studied a predominantly male sample of injury survivors assessed prior to hospital discharge and 3 and 12 months postevent. Patterns in their data also pointed to a larger resistant subgroup (these persons were low in PTSD symptoms at all time points) and a smaller subgroup with chronic dysfunction (these persons had higher levels of symptoms initially and grew more symptomatic over time). Ott, Lueger, Kelber, and Prigerson (2007) cluster analyzed longitudinal data (collected on average at 4, 9 and
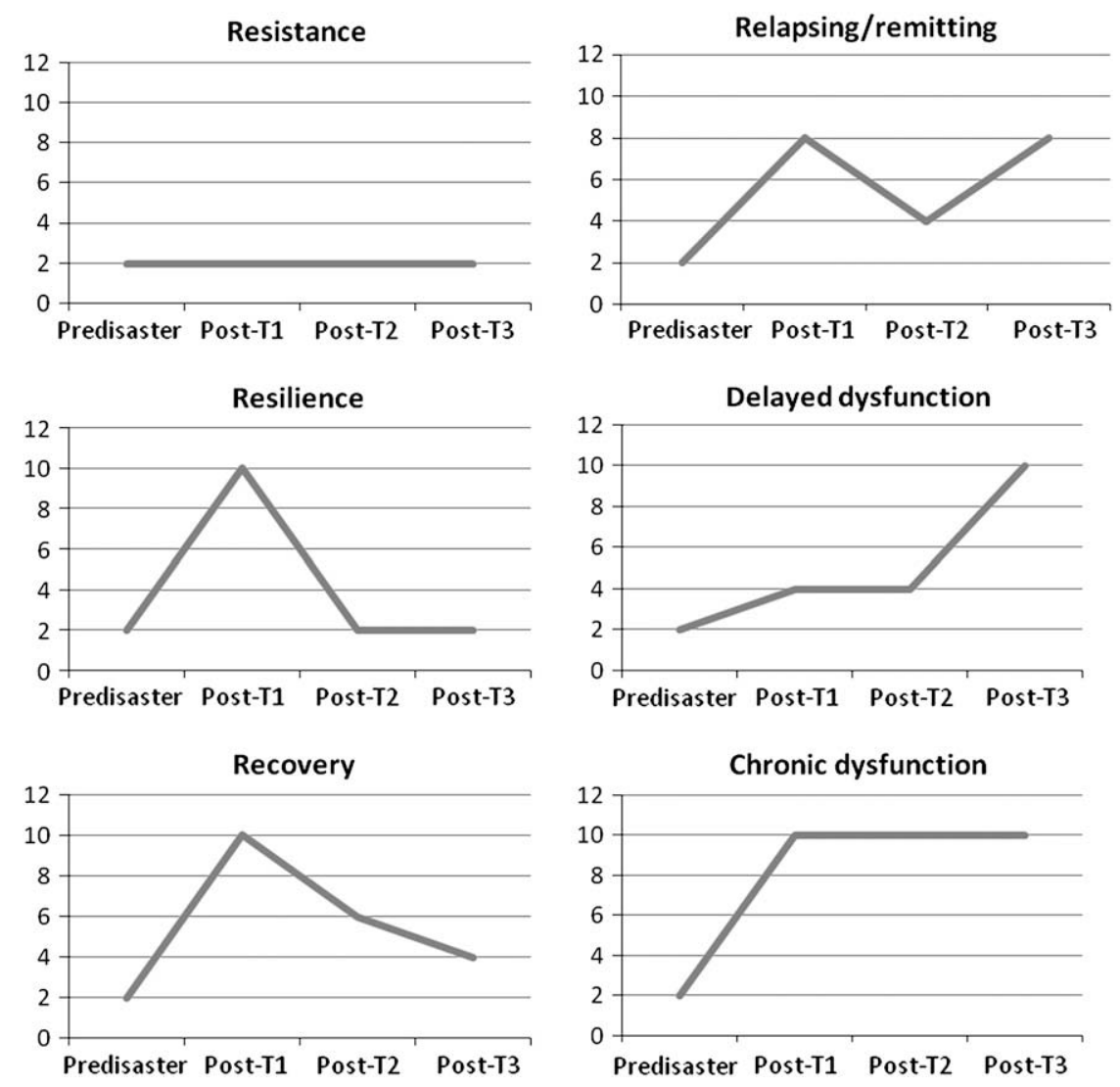

Fig. 1. Hypothesized trajectories of the course of stress responses. 
18 months postevent), from a predominantly female sample of older bereaved spouses. The largest group of participants showed "common grief" by being high in symptoms at Wave 1 followed by slow, steady improvements (recovery). The second "resilient" group was least distressed initially but nonetheless showed modest additional improvement. The third and smallest group, "chronic grief," was highly distressed at each time point, thereby showing a chronic dysfunction trajectory. Taken together, these studies well illustrate Peleg and Shalev's (2006) assertion that the study of change in symptoms as an outcome of interest in its own right is among the major shifts in PTSD research in recent years.

Despite recent advances, cross-sectional studies still make up the vast majority of research on the consequences of traumatic events and generally cannot distinguish these trajectories from one another. Nor can they distinguish delayed dysfunction from chronic dysfunction, and they may miss relapsing/remitting trajectories altogether. At minimum, such distinction requires three postevent waves to draw inferences about these trajectories; ideally, studies aiming to make this distinction would also provide pre-event measures.

In this paper, we sought to examine the presence of these various trajectories in the aftermath of disaster. Disasters are particularly interesting social phenomena where we can assess these trajectories in the general population. This context offers advantages relative to past research that has identified patterns in highly selected samples such as male combat veterans and older widows. Since disasters affect large numbers of persons, we might expect a range of trajectories to be observed that conform to all, or most of, the trajectories we hypothesize here. Therefore, we hypothesized that all patterns might occur with measurable frequency, but that resilience would be the most common pattern evidenced by populations affected by disasters. Moreover, we posited that if resilience is the expected human response to stress, it should occur reliably across disaster types and in different cultural and resource contexts. To test these ideas, we examined the trajectories of symptoms across two sharply different events in two different settings.

The first of these two events occurred in Mexico in 1999. In October of that year, a stationary tropical depression in the Gulf of Campeche generated torrential rains, widespread flooding, and devastating mudslides in nine Mexican states. To capture the variability in the way this event was experienced, we studied two different communities: Villahermosa, the capital of the coastal state of Tobasco, population 500,000, and Teziutlán, a mountain city in the state of Puebla, population 180,000. These communities anchor the geographic range of the disaster. The extent and duration of the flooding were actually worse in Villahermosa, but the sudden and unexpected mudslides in Teziutlán caused dramatic losses, bereavement, and trauma. Officials in Mexico characterized this event as the worst flooding disaster of the decade, if not of the century; more than 400 people died, and at least 200,000 people lost their homes (Red Cross, 1999).

The second of the two events was the terrorist attacks on New York City in September 2001. On the morning of September 11, 2001, four commercial airliners were hijacked from US airports. Two of the planes crashed into the twin towers of the World Trade Center (WTC) in lower Manhattan, New York City. The WTC towers collapsed in the hours after they were hit. Although most people working inside the WTC evacuated the buildings soon after the planes hit, the collapse of the towers resulted in the death of approximately 2800 people. Among the dead were office workers who were in the buildings at the time of their collapse and rescue personnel who had been climbing the towers in an attempt to bring survivors down to ground level. The attacks of September 11 were the largest single terrorist attack ever on US soil.
In this paper, we focus exclusively on trajectories of PTSD symptoms. PTSD encompasses a range of re-experiencing, avoidance, and arousal symptoms tied to a particular event (American Psychiatric Association, 1994). It is among the most prevalent psychological problems following major disasters (Galea, Nandi, \& Vlahov, 2005; Norris et al., 2002). For retrospective research on resilience, the number of disaster-related PTSD symptoms affords the advantage of a hypothetical zero mean before the event.

\section{Method}

\section{Study 1: Mexico}

\section{Sampling and interviewing procedures}

Visits to the two selected communities revealed that identical sampling procedures would not be possible. In Villahermosa, the flood damage was extensive, and victims were dispersed across a large sector of the city. The context necessitated a probability sampling design to draw a sample of adults representative of the afflicted population. From affected census tracts in Villahermosa, 653 households were sampled randomly in proportion to the tracts' population sizes. Of the 601 eligible households (non-eligible units were vacant lots or businesses), 530 were successfully contacted and the adult who answered the door was asked to provide a sociodemographic interview about the household. Of these households, 470 agreed to complete this initial interview. On the basis of the most recent birthday, one adult resident was then randomly selected from each participating household and asked to participate in an in-depth psychological interview. Of these, 461 completed the psychological interview, for a final Wave 1 response rate of $77 \%$ of those assessed as eligible and $87 \%$ of those actually contacted.

In Teziutlán, the stricken hillside communities were condemned, and all families were relocated to a new community outside of the original city. The size of the community did not necessitate sampling, and all households were included in the sampling frame. Of the 235 households provided with plots in the new community, 209 were successfully contacted. Only 1 household refused the demographic interview. Of the 208 households that completed the demographic interview, 205 participants completed the psychological interview, for a final response rate of $87 \%$ of those eligible and $98 \%$ of those actually contacted.

When the sample was compared to Mexican population data on key characteristics, the proportion of women in the sample was higher than it should have been (55\%). Analyses of the sociodemographic data indicated that the bias occurred at the point of selection for the psychological interview, although the reason for this was not clear. This selection was made at the end of the demographic interview, well after the informant had provided the birthdays, birth years, and present residence status of each household member. Fieldwork supervisors reviewed audiotapes of each interview and verified that the interviewer selected the appropriate adult (the one with the most recent birthday) for the psychological interview regardless of who gave the sociodemographic interview or who was home at the time of that initial interview. Analyses of the household demographic data indicated that female participants were quite representative of the larger population of women, but male participants underrepresented younger, lower-income, less-educated men (who are perhaps less residentially stable). With effect sizes $(d)$ in the range of $0.09-0.12$, the magnitude of the bias appeared to be quite small. To derive an unbiased population estimate, weights were applied to correct the sex distribution to a 55:45 ratio of women to men in each city.

The initial interviews were conducted 6 months postdisaster, in April 2000. Attempts were made to re-interview all participants 
12,18 , and 24 months postdisaster. In Villahermosa, 385 or $84 \%$ of the participants completed all four psychological interviews, as did 176 or $86 \%$ of the participants in Teziutlán. Attrition was unrelated to Time 1 measures of city, sex, severity of exposure, and PTSD status, $\chi^{2} s(1,666)<1.50$, ns.

All interviews were completed by trained, local interviewers in respondents' homes in private. The demographic interviews lasted about $1 \mathrm{~h}$, and psychological interviews lasted an average of $2 \mathrm{~h}$. Demographic and psychological interviews were typically completed on separate days. Fieldwork managers later revisited each participating household to deliver a letter of thanks and to ask the respondent for his or her impressions of the interview and interviewer. Study procedures were approved by institutional review boards in the United States (Georgia State University) and Mexico (University of Guadalajara and the Institute for Oaxacan Studies) and were reviewed for adherence to federal (U.S.) guidelines for conducting research in international settings.

\section{Measures}

Current (past 6-month) PTSD was measured by using a modified version of Module $\mathrm{K}$ of Version 2.1 of the Composite International Diagnostic Interview (CIDI), developed and translated into Spanish by the World Health Organization (WHO, 1997). The CIDI has been used widely in prior epidemiologic studies, including a four-city study in Mexico (Norris et al., 2003). The CIDI assesses all DSM-IV Criteria for PTSD (American Psychiatric Association, 1994) as they emerge after a specified event. To measure current disaster-related PTSD at each wave, the questions referred to symptoms attributed to the flood and experienced within the past 6 months. A count of affirmative responses to CIDI symptom questions (range 0-17) provided a continuous measure of PTSD symptoms, $\alpha=0.89$.

\section{Study 2: New York City}

\section{Sampling and interviewing procedures}

We conducted a random-digit-dial household survey to recruit baseline respondents approximately 6 months after the September 11 attacks (March 25-June 25, 2002). The sampling frame consisted of all adults ( 18 years of age and older) in the NYC metropolitan area, including the following contiguous geographic areas: New York City and Nassau, Westchester, Suffolk, and Rockland counties in New York State; Hudson, Essex, Bergen, Passaic, Union, Middlesex, Monmouth, Morris, and Somerset counties in New Jersey; Lower Fairfield county in Connecticut. Interviews were conducted in English, Spanish, Mandarin, and Cantonese by trained interviewers using translated and back-translated questionnaires and a computer-assisted telephone interview system. Households were screened for eligibility by location. If eligible, an adult in each household was randomly selected by choosing the adult whose birthday was closest to the interview date. Up to ten attempts were made to conduct the interview. The cooperation rate for the baseline survey was 56\% [cooperation rate $=$ (completed interviews + quota-outs + screen-outs)/(complete interviews + quotaouts + screen-outs + refusals + premature terminations)] and the overall response rate was $34 \%$ [response rate $=$ (completed interviews + partial interviews)/(all eligible residential telephone numbers + telephone numbers of unknown eligibility)]. Further details on sample selection are provided elsewhere (Galea et al., 2003).

Three follow-up interviews were conducted approximately 6 , 18 , and 30 months after the first interview (September 25, 2002January 31, 2003, September 25, 2003-February 29, 2004, December 15, 2004-November 30, 2005). Of the 2752 original participants, 1267 or $46 \%$ completed all four survey waves. Attrition was unrelated to Time 1 measures of area of residence, $\chi^{2}$
$(4,2752)=0.31, n s$, sex, severity of exposure, and PTSD status, $\chi^{2} s$ $(1,2752)<2.36, n s$.

Sampling weights were developed and applied to the data to correct for potential selection bias relating to the number of household telephones, persons in the household, and oversampling. We also applied post-stratification weights to make the follow-up survey samples demographically representative of the NYC metropolitan area population according to the 2000 US Census.

\section{Measures}

We used the National Women's Study (NWS) posttraumatic stress module questions to assess PTSD. This module assesses the presence of Criteria B (re-experiencing, e.g. intrusive memories, distressing dreams), C (avoidance, e.g. efforts to avoid thoughts associated with the trauma, loss of interest in significant activities), and D (arousal, e.g. difficulty falling asleep or concentrating) symptoms and determines content for content-specific symptoms (e.g., content of dreams or nightmares) if symptom presence is endorsed. Except for the time frame for reporting symptoms, the same measure was used at each wave. At the first interview, participants were asked about symptoms since the September 11, 2001 terrorist attacks; at all follow-up interviews they were asked about symptoms since the last interview. Symptom endorsement was dichotomous (yes/no); the number of symptoms endorsed and reported to be related to the September 11th attacks (range 0-17) was calculated for each survey wave. The National Women's Study PTSD module was validated in a field trial against the PTSD module of the Structured Clinical Interview for DSM-III-R administered by mental health professionals. In the field trial, instrument sensitivity was $99 \%$ and specificity was $79 \%$ (Kilpatrick et al., 1998).

For the purposes of this paper, we should note that the NWS PTSD module is very similar to the CIDI PTSD module. Both measures ask one question for each criterion symptom for a total of 17 symptom questions, use a dichotomous (yes/no) response format, and capture symptoms experienced at any time within a specified interval.

\section{Data analysis}

We used semi-parametric group-based modeling to identify trajectories of posttraumatic stress symptoms across survey waves in each of the two studies separately. All analyses were restricted to participants who completed all four survey waves. For the Mexico study, we fit censored normal models with a minimum of 0 and maximum of 17 , since posttraumatic stress symptoms were approximately normally distributed in the sample. For the New York City study, we fit zero-inflated Poisson regression models to account for the greater number of zeros in the count of posttraumatic stress symptoms than would be expected under the Poisson distribution. The Bayesian Information Criterion (BIC) was used to select the best-fitting model, with changes in the approximation to the Bayes factor greater than 10 indicating a better fit of the model with an increased number of groups (Jones, Nagin, \& Roeder, 2001); the substantive importance of the trajectory groups was also considered. After selecting the model with the optimal number of trajectory groups, we determined the appropriate shape of each trajectory group (i.e., linear, quadratic, cubic) based on statistical significance $(p<0.05)$.

In interpreting intercepts, we characterize averages of 0-3 symptoms as no or mild, 4-8 symptoms as moderate, and 9+ symptoms as severe. Although these cut-points are more-or-less arbitrary, we chose them to impose consistency in description across the two studies. This categorization was strongly related to PTSD status in the Mexico data, $\chi^{2}(4,561)=536.71, p<0.001$. Of 
persons classified as having severe distress ( $9+$ symptoms), $82 \%$ met all symptom criteria (B, C, and D), and $18 \%$ met one or two symptom criteria. Of persons classified as moderately distressed (4-8 symptoms), only $10 \%$ met all criteria, and $90 \%$ met one or two criteria. Of persons classified as having no or mild distress (0-3 symptoms), none met all criteria, 53\% met one or two symptom criteria (almost always re-experiencing, which requires only a single B symptom), and $47 \%$ met no criteria. With regard to percentages meeting all criteria for PTSD, including functioning and duration as well as symptoms, these values were $51 \%, 3 \%$, and $0 \%$ for severe, moderate, and no-mild distress categories, $\chi^{2}$ $(2,561)=214.35, p<0.001$.

\section{Results}

\section{Study 1: Mexico}

The 561 residents of Villahermosa and Teziutlán who completed all four interviews averaged 37 years of age $(S D=13)$ and 8 years of education $(\mathrm{SD}=5)$ and were $55 \%$ female. Disaster-related bereavement was experienced by $28 \%$, life threat by $70 \%$, and much or enormous property damage by $48 \%$. Of persons who reported at least one PTSD symptom, 68\% reported that the problems began within a week of the event, $81 \%$ within a month. Of these same persons, $48 \%$ reported that the problems stopped within 1 month of their onset. Across the four intervals, $17 \%, 10 \%, 8 \%$, and $9 \%$ reported having consulted a medical doctor about their disaster-related symptoms, and $9 \%, 6 \%, 3 \%$, and $1 \%$ reported having consulted some other professional. This profession was a natural healer or religious leader more often than a psychiatrist or psychologist $(n=8)$.

Model comparisons using the BIC indicated that five trajectory groups provided the best fit to the patterns of posttraumatic stress symptoms in the sample (Fig. 2). As shown in Table 1, three of the five groups were defined by the intercept parameter only (Groups 1 , 2 , and 5), indicating a stable number of symptoms throughout the study period. These included a group characterized by approximately 2 posttraumatic stress symptoms during the study period and comprising $35 \%$ of the sample (Group 1, mild and stable),

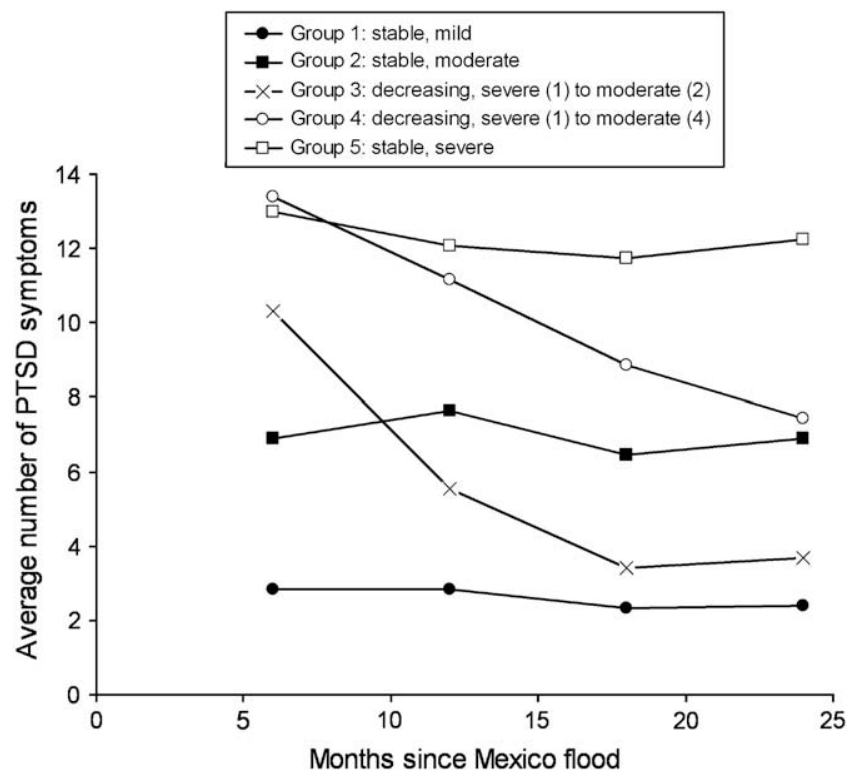

Fig. 2. Trajectories of PTSD symptoms among residents of Villahermosa and Teziutlán in Mexico $(n=561)$ after the 1999 flood. Numbers in parentheses refer to the wave of assessment. a group exhibiting 7 posttraumatic stress symptoms throughout the study period and comprising $12 \%$ of the sample (Group 2, moderate and stable), and a group exhibiting 12 posttraumatic stress symptoms throughout the study and comprising $10 \%$ of the sample (Group 5, severe and stable). The remaining two groups exhibited declines in symptoms. Group 3, comprising 32\% of the sample, showed a severe level of symptoms (10 symptoms) during the first 6 months after the disaster, but their symptoms declined to moderate levels ( 6 symptoms) by 12 months and to mild levels (3 symptoms) by 18 months, where they stabilized, thereby creating a quadratic trend. Group 4 , comprising $11 \%$ of the sample, showed symptoms as high as the stable severe group at 6 months (13 symptoms), but their symptoms declined gradually in a linear fashion throughout the study period, reaching a moderate level (7 symptoms) by 24 months post. The mean posterior probabilities of group assignment ranged from 0.702 to 0.926 for the five trajectory groups.

\section{Study 2: New York City}

The 1267 residents of the New York City metropolitan area who completed all four survey waves averaged 44 years of age $(S D=16)$ and were 55\% female, 63\% non-Hispanic White, 15\% African American, $12 \%$ Hispanic, and $9 \%$ Asian or other race/ethnicity. Only $7 \%$ of the sample reported having less than a high school education, and $69 \%$ had at least some college education. Nearly a third of the sample (29\%) was directly affected by the September 11, 2001 attacks, including being present in the World Trade Center at the time of the attacks, being physically injured, having a relative or friend killed, having possessions lost or damaged, losing a job as a result of the attacks, or being involved in the rescue or recovery efforts. However, it is important to note that all participants potentially experienced fear and uncertainty related to the attacks. Across the four intervals, $1.3 \%, 1.5 \%, 1.4 \%$, and $1.7 \%$ of the sample reported having consulted a physician about their September 11th attack-related symptoms, and $1.9 \%, 2.2 \%, 1.6 \%$, and $1.2 \%$ reported having consulted a psychiatrist or psychologist. Additionally, $2.8 \%$, $2.7 \%, 1.4 \%$, and $1.9 \%$ reported having consulted some other professional, most commonly a counselor, social worker, or minister.

Seven trajectory groups emerged as optimal to describe the patterns of September 11, 2001 related posttraumatic stress symptoms in the sample (Fig. 3 and Table 2). Group 1 comprised $40 \%$ of the sample and was characterized by virtually no posttraumatic stress symptoms during the study period, defined by only an intercept term. Two groups (Groups 3 and 6) exhibited declines in posttraumatic stress symptoms; both were defined by a quadratic trajectory and started from an initial level of approximately 4 symptoms at 6 months post. Group 3 (10\% of the sample) decreased to $<1$ symptom by 12 months and remained there for the rest of the study period, whereas Group 6 (9\% of the sample) exhibited a more gradual recovery, with about 2 symptoms still reported by group members by the end of the study period.

Three of the trajectory groups were characterized by increases in posttraumatic stress symptoms during the study period, with cubic trends providing the best fit for each of these three groups. Group 2 ( $13 \%$ of the sample) increased from 0 symptoms at Time 1 to an average of 2 symptoms approximately 12 months after the September 11th attacks and remained at this mild level of symptoms throughout the remainder of the study period. Group 4 ( $14 \%$ of the sample) exhibited a mild level of 2 symptoms during the first 2 years but increased to a moderate level of 4 symptoms by the end of the study period. Group 5 (10\% of the sample) started at a moderate level of 5 symptoms and continued to increase, reporting a still moderate but higher level of 8 symptoms by the end of the study period. 
Table 1

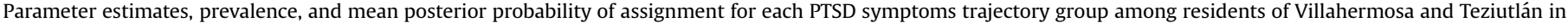
Mexico $(n=561)$ after the 1999 flood.

\begin{tabular}{|c|c|c|c|c|c|c|}
\hline Group & Symptom trajectory ${ }^{\mathrm{a}}$ & Parameter & Estimate $(\mathrm{SE})^{\mathrm{b}}$ & $p$-Value & Prevalence & $\begin{array}{l}\text { Mean posterior } \\
\text { probability }(S D)^{c}\end{array}$ \\
\hline 1 & Stable, mild & Intercept & $2.308(0.161)$ & $<0.001$ & $34.5 \%$ & $0.926(0.133)$ \\
\hline 2 & Stable, moderate & Intercept & $6.881(0.699)$ & $<0.001$ & $12.0 \%$ & $0.702(0.163)$ \\
\hline 3 & $\begin{array}{l}\text { Decreasing, severe ( } 1) \\
\text { to moderate }(2)\end{array}$ & $\begin{array}{l}\text { Intercept } \\
\text { Linear } \\
\text { Quadratic }\end{array}$ & $\begin{array}{r}17.686(0.991) \\
-1.453(0.130) \\
0.036(0.004)\end{array}$ & $\begin{array}{l}<0.001 \\
<0.001 \\
<0.001\end{array}$ & $\begin{array}{l}32.0 \% \\
- \\
-\end{array}$ & $\begin{array}{l}0.821(0.180) \\
- \\
-\end{array}$ \\
\hline 4 & $\begin{array}{l}\text { Decreasing, severe (1) } \\
\text { to moderate ( } 4 \text { ) }\end{array}$ & $\begin{array}{l}\text { Intercept } \\
\text { Linear }\end{array}$ & $\begin{array}{r}15.377(1.355) \\
-0.343(0.079)\end{array}$ & $\begin{array}{l}<0.001 \\
<0.001\end{array}$ & $\begin{array}{l}11.4 \% \\
-\end{array}$ & $\begin{array}{l}0.818(0.146) \\
-\end{array}$ \\
\hline 5 & Stable, severe & Intercept & $12.343(0.393)$ & $<0.001$ & $10.0 \%$ & $0.827(0.161)$ \\
\hline
\end{tabular}

a Mild: 0-3 symptoms; moderate: 4-8 symptoms; severe: $\geq 9$ symptoms; numbers in parentheses indicate survey wave.

b Standard error.

c Standard deviation.

Finally, as in the Mexico study, one group was characterized by a consistently severe level of posttraumatic stress, approximately 12 symptoms, throughout the study period (Group 7; 3\% of the sample); a quadratic trajectory provided the best fit for the pattern exhibited by this group. The mean posterior probabilities of group assignment ranged from 0.806 to 0.937 for the seven trajectory groups.

\section{Observed and hypothesized trajectories}

Table 3 relates the trajectories observed in Mexico and New York back to the hypothesized trajectories shown in idealized form in Fig. 1. The strongest evidence emerged for resistance (mild and stable symptoms: Mexico Group 1, New York Groups 1 and 2), resilience (moderate or severe symptoms at the first postevent interview followed by a sharp decrease: Mexico Group 3, New York Group 3), recovery (moderate or severe with gradual decrease: Mexico Group 4, New York Group 6), and chronic dysfunction (moderate or severe and stable symptoms: Mexico Groups 2 and 5, New York Groups 5 and 7) trajectories, which were prevalent in both samples. Neither Mexico nor New York showed a relapsing/

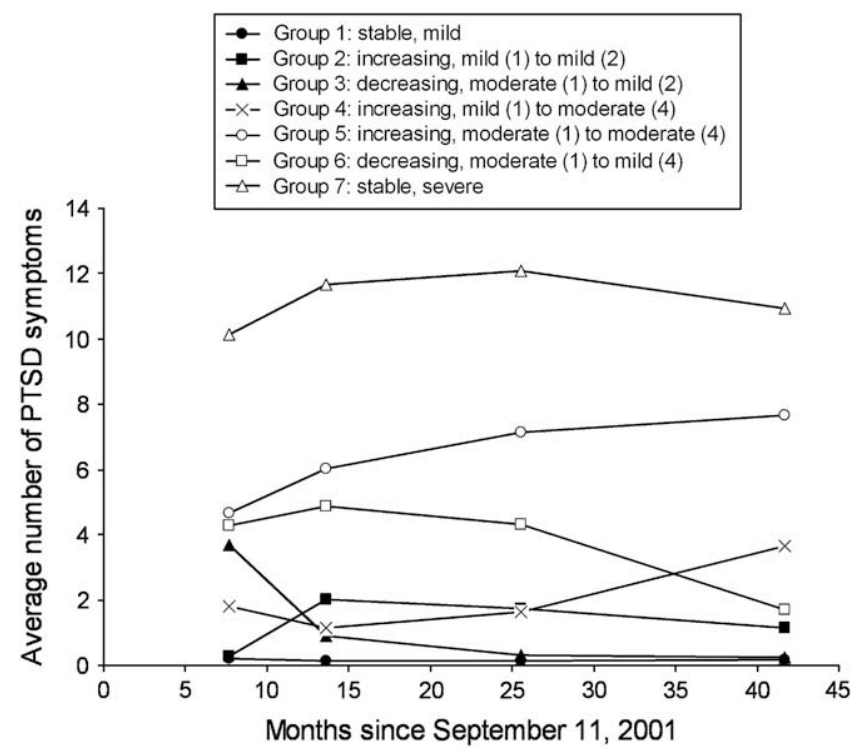

Fig. 3. Trajectories of PTSD symptoms among residents of the New York City metropolitan area $(n=1,267)$ after the September 11, 2001 attacks. Numbers in parentheses refer to the wave of assessment. remitting trajectory, and only New York showed a delayed dysfunction trajectory (Group 4).

\section{Discussion}

Taking advantage of two longitudinal datasets, we sought in this study to examine the notion that resilience may be best understood and measured as one member of a set of trajectories that may follow exposure to trauma or severe stress. We had hypothesized that resistance, resilience, recovery, relapsing/remitting, delayed dysfunction, and chronic dysfunction trajectories were all possible in the aftermath of major disasters. With one exception (relapsing/ remitting), all of the hypothesized trajectories (Fig. 1) occurred in the data with measurable frequency.

Even though both of the studied events were quite serious, from one third (Mexico) to one half (New York) of these participants exhibited resistance by never showing more than mild distress, operationally defined as $\leq 3$ PTSD symptoms. On the basis of past disaster research that has focused on sample averages, we expected to see relatively little resistance, as many longitudinal studies have shown a pattern of higher initial symptoms that dissipate over time (see Norris et al., 2002). The present analyses, however, have shown that a substantial subset of the stricken population may exhibit trends that do not conform to this generalized result. As defined here, resistance does not preclude the existence of some mild distress or even the presence of minor fluctuations within the mild range. Although we have characterized this trajectory as resistance, it is similar to the definition of resilience provided by Bonanno (2004) as an individual's capacity to maintain healthy symptom-free functioning following stressful life events. However, in keeping with the important distinction between stability and adaptability for understanding divergent responses to stress, we argued that stability would be better characterized as resistance and adaptability as resilience, and therefore the latter concept would be more appropriately used to describe the capacity to quickly rebound from an initial experience of distress created by an environmental change.

Perhaps because of the unexpectedly high prevalence of resistance, the prevalence of resilience was lower than anticipated, at least in New York, where the prevalence was only $10 \%$. This group never showed severe distress but rather began with moderate distress, rapidly improved to mild distress, and subsequently showed no distress. In Mexico, the prevalence of resilience was substantial (32\%); this group initially showed severe distress, operationally defined as $\geq 9$ PTSD symptoms, but improved rapidly, showing only moderate distress (4-8 PTSD symptoms) at Wave 2. However, it took another few months for this group to resemble the 
Table 2

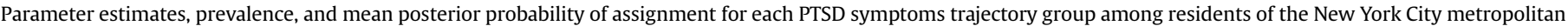
area $(n=1,267)$ after the September 11, 2001 attacks.

\begin{tabular}{|c|c|c|c|c|c|c|}
\hline Group & Symptom trajectory ${ }^{\mathrm{a}}$ & Parameter & Estimate $(\mathrm{SE})^{\mathrm{b}}$ & $p$-Value & Prevalence & $\begin{array}{l}\text { Mean posterior } \\
\text { probability }(\mathrm{SD})^{\mathrm{C}}\end{array}$ \\
\hline$\overline{1}$ & Stable, mild & Intercept & $-1.847(0.174)$ & $<0.001$ & $40.1 \%$ & $0.921(0.135)$ \\
\hline 2 & $\begin{array}{l}\text { Increasing, mild (1) } \\
\text { to mild ( } 2 \text { ) }\end{array}$ & $\begin{array}{l}\text { Intercept } \\
\text { Linear } \\
\text { Quadratic } \\
\text { Cubic }\end{array}$ & $\begin{array}{r}-7.617(3.239) \\
1.108(0.433) \\
-0.044(0.016) \\
0.001(0.0002)\end{array}$ & $\begin{array}{l}0.019 \\
0.011 \\
0.006 \\
0.003\end{array}$ & $\begin{array}{l}13.3 \% \\
- \\
- \\
-\end{array}$ & $\begin{array}{l}0.806(0.179) \\
- \\
- \\
-\end{array}$ \\
\hline 3 & $\begin{array}{l}\text { Decreasing, moderate ( } 1 \text { ) } \\
\text { to mild ( } 2)\end{array}$ & $\begin{array}{l}\text { Intercept } \\
\text { Linear } \\
\text { Quadratic }\end{array}$ & $\begin{array}{r}3.210(0.573) \\
-0.291(0.066) \\
0.004(0.001)\end{array}$ & $\begin{array}{l}<0.001 \\
<0.001 \\
<0.001\end{array}$ & $\begin{array}{l}10.1 \% \\
- \\
-\end{array}$ & $\begin{array}{l}0.834(0.175) \\
- \\
-\end{array}$ \\
\hline 4 & $\begin{array}{l}\text { Increasing, mild ( } 1 \text { ) } \\
\text { to moderate ( } 4)\end{array}$ & $\begin{array}{l}\text { Intercept } \\
\text { Linear } \\
\text { Quadratic } \\
\text { Cubic }\end{array}$ & $\begin{array}{c}2.360(0.812) \\
-0.335(0.133) \\
0.015(0.006) \\
-0.0002(0.00008)\end{array}$ & $\begin{array}{l}0.004 \\
0.011 \\
0.015 \\
0.029\end{array}$ & $\begin{array}{l}14.3 \% \\
- \\
- \\
-\end{array}$ & $\begin{array}{l}0.829(0.175) \\
- \\
- \\
-\end{array}$ \\
\hline 5 & $\begin{array}{l}\text { Increasing, moderate ( } 1 \text { ) } \\
\text { to moderate ( } 4 \text { ) }\end{array}$ & $\begin{array}{l}\text { Intercept } \\
\text { Linear } \\
\text { Quadratic } \\
\text { Cubic }\end{array}$ & $\begin{array}{c}0.320(0.504) \\
0.195(0.056) \\
-0.007(0.002) \\
0.00009(0.00003)\end{array}$ & $\begin{array}{l}0.525 \\
0.001 \\
0.001 \\
0.001\end{array}$ & $\begin{array}{l} \\
- \\
- \\
- \\
-\end{array}$ & $\begin{array}{l}0.878(0.139) \\
- \\
- \\
-\end{array}$ \\
\hline 6 & $\begin{array}{l}\text { Decreasing, moderate ( } 1 \text { ) } \\
\text { to mild ( } 4)\end{array}$ & $\begin{array}{l}\text { Intercept } \\
\text { Linear } \\
\text { Quadratic }\end{array}$ & $\begin{array}{r}0.885(0.305) \\
0.079(0.025) \\
-0.002(0.001)\end{array}$ & $\begin{array}{r}0.004 \\
0.001 \\
<0.001\end{array}$ & $\begin{array}{l}9.3 \% \\
- \\
-\end{array}$ & $\begin{array}{l}0.862(0.152) \\
- \\
-\end{array}$ \\
\hline 7 & Stable, severe & $\begin{array}{l}\text { Intercept } \\
\text { Linear } \\
\text { Quadratic }\end{array}$ & $\begin{array}{c}2.049(0.215) \\
0.039(0.015) \\
-0.001(0.0002)\end{array}$ & $\begin{array}{r}<0.001 \\
0.008 \\
0.002\end{array}$ & $\begin{array}{l}3.1 \% \\
- \\
-\end{array}$ & $\begin{array}{l}0.937(0.104) \\
- \\
-\end{array}$ \\
\hline
\end{tabular}

a Mild: 0-3 symptoms; moderate: 4-8 symptoms; severe: $\geq 9$ symptoms; numbers in parentheses indicate survey wave.

b Standard error.

c Standard deviation.

resistant group by showing only mild distress. This interpretation of the data from Mexico reflects a somewhat relativistic conceptualization of resilience, as even in the resilient group, the "bouncing back" took place over many months. It could be argued that Mexico had two recovery subgroups and no incontrovertible trajectory of resilience.

Theoretically, recovery differs from resilience primarily in the speed of improvement, i.e., recovery takes place more gradually, over a longer interval of time. The prevalence of recovery in Mexico was $11 \%$; this group improved from severe to moderate distress during the course of the study, which concluded at 2 years postdisaster; extrapolation of the recovery trajectory indicates that it might take another year or two (i.e., until 3-4 years postdisaster) for this group to reach the mild levels of distress experienced by the resistant and resilient groups at 2 years post. The prevalence of recovery in New York (9\%) was about the same as in Mexico, and most of this group's improvement took place between 2 and 3.5 years post. In New York, the difference between the resilience (Group 4) and recovery (Group 6) trajectories was especially clear

Table 3

Observed trajectories in Mexico and New York classified according to the hypothesized trajectories.

\begin{tabular}{|c|c|c|c|c|}
\hline \multirow{2}{*}{$\begin{array}{l}\text { Hypothesized } \\
\text { trajectory (Fig. 1) }\end{array}$} & \multicolumn{2}{|l|}{ Mexico } & \multicolumn{2}{|l|}{ New York } \\
\hline & $\begin{array}{l}\text { Observed trajectory } \\
\text { (Groups, Fig. 2) }\end{array}$ & Total \% & $\begin{array}{l}\text { Observed trajectory } \\
\text { (Groups, Fig. 3) }\end{array}$ & Total \% \\
\hline Resistance & 1 & 34.5 & 1,2 & 53.4 \\
\hline Resilience & 3 & 32.0 & 3 & 10.1 \\
\hline Recovery & 4 & 11.4 & 6 & 9.3 \\
\hline $\begin{array}{l}\text { Relapsing } \\
\text { /remitting }\end{array}$ & & 0.0 & & 0.0 \\
\hline $\begin{array}{l}\text { Delayed } \\
\text { dysfunction }\end{array}$ & & 0.0 & 4 & 14.3 \\
\hline $\begin{array}{l}\text { Chronic } \\
\text { dysfunction }\end{array}$ & 2,5 & 22.0 & 5,7 & 13.0 \\
\hline
\end{tabular}

because the two groups' initial level of symptoms was virtually identical. Although resistance, resilience, and recovery trajectories have different implications for illness burden, they may be considered together as good outcomes. Their combined prevalence was high in both Mexico (78\%) and New York (72\%).

Neither the Mexico nor the New York analysis yielded a group that could be characterized as relapsing/remitting. Our studies may have lacked the ability to detect this trajectory, as the measures were unlikely to identify individuals who worsened, but then improved, within an interval. And, possibly, the duration of the studies (2 years in Mexico, 3 in New York) was not long enough to detect later relapses. Examples of relapsing/remitting trajectories are few in disaster research, but Phifer and Norris (1989) alluded to such patterns in their longitudinal study of older adults after a late-spring flood in Eastern Kentucky. In that study, mean symptoms peaked at the second postdisaster wave (in the spring after the flood) and showed a secondary peak two waves later during the following spring, raising the question that the heavy rains typical of spring in the mountains served as reminders of the earlier, more severe flood. Anecdotally, service providers often express concerns about "anniversary effects" that could be evidenced as relapsing/ remitting patterns.

Perhaps the most surprising finding of the study was the substantial prevalence of delayed dysfunction in New York (14\%). However, the New York results are actually quite consistent with the conclusions drawn by Andrews, Brewin, Philpott, and Stewart (2007) on the basis of their review of the literature on delayedonset PTSD. They noted that delayed onset of PTSD is rare in the absence of any prior symptoms, but accounts for approximately $15 \%$ of civilian trauma cases when delayed onsets are defined to include exacerbations of prior symptoms. They also noted that little is known about what distinguishes the delayed form of the disorder from the more typical immediate-onset form.

Finally, chronic dysfunction trajectories were evident in both Mexico (22\%) and New York (13\%). In Mexico, this included one 
group with stable and severe symptoms (10\%) and a second group with stable and moderate symptoms (12\%). In New York this included one group with stable and severe symptoms (3\%) and a second group with moderate symptoms that worsened but stayed within the moderate range (10\%). Although they constitute only a minority of the population, individuals who fail to recover are extremely important for planning health and mental health care. The identification of predictors of group membership is beyond the purpose of this particular paper, but past research suggests that a trajectory of chronic dysfunction is likely the result of severe initial exposure to the disaster in combination with ongoing adversities and secondary stressors (Galea, Tracy, Norris, \& Coffey, 2008; Norris et al., 2002).

Our studies had several key strengths, especially compared to the norms in disaster research (see Norris, 2006). First, we used data from two studies with four-wave longitudinal designs. Only about one in four disaster studies are longitudinal and only one in ten have at least three postdisaster waves, the minimum number of time points required to distinguish the hypothesized trajectories from one another. Second, both the Mexico and New York studies were population-based. Randomly selected population samples account for only about one in five disaster studies, and previous studies of the trajectories of trauma recovery have focused exclusively on selected groups, such as male combat veterans, hospitalized injury survivors, or older bereaved spouses. This attribute of our studies allowed us to consider the prevalence of various trajectories in the general population. Third, although we lacked pre-disaster measures, our measures of PTSD were event-specific and thus overcame the problem to the extent possible. It is worth noting that our assessment of trajectories rests on the assumption that we are capturing only new postevent symptoms (there is a hypothetical 0 symptoms point in each group at Month 0 ). This would not be the case if we had assessed depression or anxiety symptoms that occur with some frequency in populations and are not explicitly linked to disaster or trauma. However, we cannot rule out the potential for false attributions of the cause or onset of symptoms. Fourth, our measures of PTSD assessed intervals (e.g., past 6 months) rather than points (e.g., past week). If we had assessed only those symptoms present at the times of the interviews, we would have missed PTSD symptoms that were present earlier in the intervals and possibly failed to detect resilience. This feature was especially important at Wave 1 , as we captured symptoms experienced within days of the event. The retrospective nature of the assessment was an unavoidable shortcoming of these studies. More assessments of shorter intervals would provide superior data, but the cost and participant burden are prohibitive. Finally, the focus on mass disaster as the stressor largely eliminates concerns that the stressor, or the timing of its occurrence, is somehow confounded with person characteristics or pre-existing developmental trajectories. By considering two different types of disasters in different contexts (Mexico, natural disaster; New York, terrorist attack), we gain greater confidence in the generalizability of the results. However, these results do not necessarily generalize to other types of events, such as sexual assault or other forms of interpersonal violence.

Other than the shortcomings previously acknowledged, the primary weakness of the approach used here was its subjectivity. The labels applied in Figs. 2 and 3 were value-neutral, but the act of relating the observed trajectories back to the hypothesized trajectories involved interpretation. As we noted in the case of Mexico, the resilience and recovery trajectories were not as dramatically different as would be ideal. In real life, the timing of recovery is more likely to be a continuum than a categorical variable. Another potential issue is that between-setting differences could be attributable to methods. Although they are quite similar, the NWS and CIDI PTSD modules are not identical, and the methods of data collection differed (phone in New York, face-to-face in Mexico). Another shortcoming is that the measures captured only the presence rather than severity of each symptom. Additionally, group-based trajectory modeling may find only local minima, leaving the possibility of a different true pattern of trajectory groups than observed in these analyses; however, the optimal number of trajectory groups for each study was robust across different starting values for each trajectory, which provides some evidence that the procedure did not find only local minima (Jones et al., 2001).

Our paper also has three limitations in terms of its scope. First, we focused solely on individual-level differences in recovery trajectories, but we do not mean to imply that resilience is fundamentally a characteristic of the person. A host of adaptive capacities (e.g., economic resources, social capital) functions at the community level to promote or impede individual and population resilience and recovery (Norris et al., 2008). Second, we focused solely on the total number of PTSD symptoms as the outcome of interest. Different trajectories might have emerged for different PTSD clusters, such as re-experiencing or avoidance, or for different outcomes, such as depression or somatic complaints. Nor did we consider the related question of posttraumatic growth. Third, we focused solely on determining the prevalence of the hypothesized trajectories, rather than on their determinants. Identifying the environmental, social, psychological, and biological determinants of these trajectories is an important direction for future research.

In conclusion, our research helps to define "resilience" not as a somewhat circular explanation for the absence of psychopathology, but as one specific trajectory that can be identified, measured, distinguished from other trajectories, and studied across stressors and settings. Distinctions between various postevent symptom trajectories are important because it is quite likely that the three trajectories that yield good long-term outcomes (resistance, resilience, recovery) have different determinants and are best promoted by different intervention strategies introduced at different times. Postdisaster interventions must occur at multiple levels (individual, family, community) and evolve over time, as needs change. Whereas resistance is the hypothetical ideal, the best possible outcome of mass trauma intervention is not always resistance, nor is it always resilience. Nevertheless, appropriate interventions should increase the likelihood of resilience among people who are not resistant and the likelihood of recovery among people who are not resilient (Norris \& Stevens, 2008). Both secondary and tertiary prevention strategies, if efficacious and effective, have a place in the continuum of postdisaster health care.

\section{References}

Adger, W. (2000). Social and ecological resilience: are they related? Progress in Human Geography, 24, 347-364.

American Psychiatric Association. (1994). Diagnostic and statistical manual of mental disorders (4th ed.). Washington, DC: Author.

Andrews, B., Brewin, C., Philpott, R., \& Stewart, L. (2007). Delayed-onset posttraumatic stress disorder: a systematic review of the evidence. American Journal of Psychiatry, 164, 1319-1326.

Bodin, P., \& Wiman, B. (2004). Resilience and other stability concepts in ecology: notes on their origin, validity, and usefulness. ESS Bulletin, 2, 33-43.

Bonanno, G. (2004). Loss, trauma, and human resilience: have we underestimated the human capacity to thrive after extremely aversive events? American Psychologist, 59, 20-28.

Breslau, N., Kessler, R., Chilcoat, H., Schultz, L., Davis, G., \& Andreski, P. (1998). Trauma and posttraumatic stress disorder in the community. The 1996 Detroit Area Survey of Trauma. Archives of General Psychiatry, 55, 627-632.

Butler, L., Morland, L., \& Leskin, G. (2007). Psychological resilience in the face of terrorism. In B. Bongar, L. Brown, L. Beutler, J. Breckenridge, \& P. Zimbardo (Eds.), Psychology of terrorism (pp. 400-417). NY: Oxford University Press.

Cowen, E., Wyman, P., \& Work, W. (1996). Resilience in highly stressed urban children: concepts and findings. Bulletin of the New York Academy of Medicine, 73, 267-284. 
Egeland, B., Carlson, E., \& Sroufe, L. (1993). Resilience as process. Development $\mathcal{E}^{\prime}$ Psychopathology, 5, 517-528.

Flynn, B. (1994). Mental health services in large scale disasters: an overview of the Crisis Counseling Program. NCP Clinical Quarterly, 4, 1-4.

Galea, S., Nandi, A., \& Vlahov, D. (2005). The epidemiology of post-traumatic stress disorder after disaster. Epidemiologic Reviews, 27, 1-14.

Galea, S., Tracy, M., Norris, F., \& Coffey, S. (2008). Financial and social circumstances, the incidence and course of PTSD in Mississippi during the first two years after Hurricane Katrina. Journal of Traumatic Stress, 21, 357-368.

Galea, S., Vlahov, D., Resnick, H., Ahern, J., Susser, E., Gold, J., et al. (2003). Trends of probable post-traumatic stress disorder in New York City after the September 11 terrorist attacks. American Journal of Epidemiology, 158, 514-524.

Garmezy, N. (1974). The study of competence in children at risk for severe psychopathology. In E. Anthony, \& C. Koupernik (Eds.), Children at psychiatric risk. The child in his family, Vol. 3 (pp. 77-97). New York: Wiley.

Garmezy, N. (1993). Children in poverty: resilience despite risk. Psychiatry: Interpersonal and Biological Processes, 56, 127-136.

Jones, B. L., Nagin, D. S., \& Roeder, K. (2001). A SAS procedure based on mixture models for estimating developmental trajectories. Sociological Methods $\mathcal{E}$ Research, 29, 374-393.

Kilpatrick, D. G., Resnick, H. S., Freedy, J. R., Pelcovitz, D., Resick, P., Roth, S., et al. (1998). The posttraumatic stress disorder field trial: evaluation of the PTSD construct criteria A through E. In T. Widiger, A. Frances, \& H. A. Pincus (Eds.), DSM-IV sourcebook, Vol. 4 (pp. 803-844). Washington, DC: American Psychiatric Association Press.

Klein, R., Nicholls, R., \& Thomalla, F. (2003). Resilience to natural hazards: how useful is this concept? Environmental Hazards, 5, 35-45.

Layne, C. M., Warren, J. S., Watson, P. J., \& Shalev, A. Y. (2007). Risk, vulnerability, resistance, and resilience: toward an integrative conceptualization of posttraumatic adaptation. In M. Friedman, T. Keane, \& P. Resick (Eds.), Handbook of PTSD: Science and practice (pp. 497-520). New York: Guilford Press.

Masten, A., Best, K., \& Garmezy, N. (1990). Resilience and development: contributions from the study of children who overcome adversity. Development $\mathcal{E}$ Psychopathology, 2, 425-444.

Norris, F. (2006). Disaster research methods: past progress and future directions. Journal of Traumatic Stress, 19, 173-184.
Norris, F., Friedman, M., Watson, P., Byrne, C., Diaz, E., \& Kaniasty, K. (2002). 60,000 Disaster victims speak: part I, an empirical review of the empirical literature 1981-2001. Psychiatry: Interpersonal and Biological Processes, 65, 207-239.

Norris, F., Murphy, A., Baker, C., Perilla, J., Gutierrez-Rodriguez, F., \& GutierrezRodriguez, J. (2003). Epidemiology of trauma and posttraumatic stress disorder in Mexico. Journal of Abnormal Psychology, 112, 646-656.

Norris, F., \& Stevens, S. (2008). Community resilience and the principles of mass trauma intervention. Psychiatry: Interpersonal and Biological Processes, 70, 320-328.

Norris, F., Stevens, S., Pfefferbaum, B., Wyche, K., \& Pfefferbaum, R. (2008) Community resilience as a metaphor, theory, set of capacities, and strategy for disaster readiness. American Journal of Community Psychology, 41, 127-150.

O’Donnell, M. L., Elliott, P., Lau, W., \& Creamer, M. C. (2007). PTSD symptom trajectories: from early to chronic response. Behaviour Research and Therapy, 45(3), 601-606

Orcutt, H. K., Erickson, D. J., \& Wolfe, J. (2004). The course of PTSD symptoms among gulf war veterans: a growth mixture modeling approach. Journal of Traumatic Stress, 17, 195-202.

Ott, C. H., Lueger, R. J., Kelber, S. T., \& Prigerson, H. G. (2007). Spousal bereavement in older adults: common, resilient, and chronic grief with defining characteristics. Journal of Nervous and Mental Disease, 195(4), 332-341.

Peleg, T., \& Shalev, A. Y. (2006). Longitudinal studies of PTSD: overview of findings and methods. CNS Spectrums, 11(8), 589-602.

Phifer, J., \& Norris, F. (1989). Psychological symptoms in older adults following disaster: nature, timing, duration, and course. Journal of Gerontology: Social Science, 44, 207-217.

Red Cross. (1999). Mexico flood victims mourn dead, plead for help. Retrieved October 11, 1999 from. www.DisasterRelief.org/Disasters/991011Mexico.

van der Velden, P., Christiaanse, B. B. A., Kleber, R. J., Marcelissen, F. G. H Dorresteijn, S. A. M., Drogendijk, A. N., et al. (2006). The effects of disaster exposure and post-disaster critical incidents on intrusions, avoidance reactions and health problems among firefighters: a comparative study. Stress, $9(2)$.

Werner, E. E., \& Smith, R. S. (1982). Vulnerable but invincible: A longitudinal study of resilient children and youth. New York: McGraw-Hill.

World Health Organization. (1997). Composite International Diagnostic Interview (CIDI). Version 2.1. Geneva: World Health Organization. 